\title{
Система психологического сопровождения образования детей с задержкой психического развития
}

\author{
Наталия В. Бабкина \\ ФГБНУ «Институт коррекционной педагогики Российской академии образования», \\ г. Москва, Российская Федерация \\ E-mail: natali.babkina@mail.ru
}

\begin{abstract}
Аннотация
Введение. В статье обсужАаются вопросы, связанные с проблемой психологического сопровожАения наиболее представленной в инкАюзивной образовательной среле категории школьников - Аетей с залержкой психического развития (ЗПР). Новизна исслеАования заключается в проектировании целостной системы Аифореренцированного психологического сопровожАения образования Аанной категории Аетей с учетом вариативности их развития к началу школьного обучения, а также в вылелении и описании основных видов и направлений Аеятельности пелагога-психолога.
\end{abstract}

Теоретическое обоснование. ПреАставлены методологические основы исслеАОвания, вк^ючающие: базовые положения специальной психологии и коррекционной педагогики, основанные на культурно-исторической теории А. С. Выготского; социокультурный поАхоА к анализу развития образовательной практики и залачам специальной психологии на кажАОМ этапе развития системы образования Аетей с ограниченными возможностями зАоровья; метоАологию психологического сопровожАения в рамках образовательного процесса. Описываются современные подходы к целям и организации психологического сопровожАения Аетей с залержкой психического развития в связи с модернизацией системы образования, анализируются необходимое солержание и условия образования м^аАших школьников, направленные на удовлетворение их особых образовательных потребностей.

Результаты и их обсужАение. Авторы рассматривают психологическое сопровожАение Аетей с залержкой психического развития как планомерную реализацию основных виАОв профрессиональной Аеятельности психолога, Аиффреренцированных в соответствии с актуальными залачами современной образовательной практики и способствующих в своей совокупности успешному обучению и развитию кажАого ребенка. В качестве основных залач сопровожАения вылеляются: выявление, устранение и предотвращение лисбаланса между процессами обучения и развития Аетей с учетом их инАивиАуальных возможностей; коррекция 


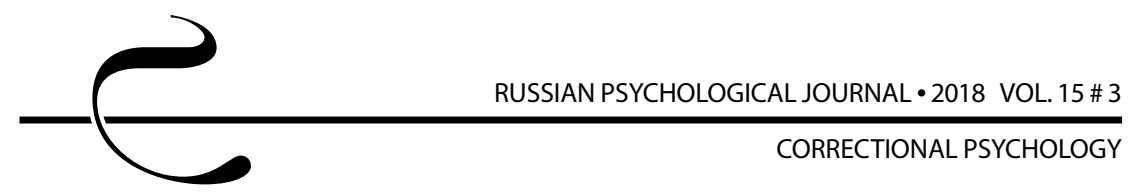

вторичных нарушений развития, проявляющихся в когнитивной, эмоционаАьной и социально-поведенческой сорерах; создание условий Аля социально-психологической адаптации мичности ребенка. Обосновываются основные виАы Аеятельности психолога: Аиагностическая, коррекционно-развивающая, экспертно-консультативная. В заключении приводятся критерии оценки эфффективности психологического сопровожАения.

\section{КАючевые слова}

модернизация образования, инкмюзия, задержка психического развития, особые образовательные потребности, психологическое сопровождение, фуннкционал психолога, Аифрференцированный подхоА, Аиагностическая Аеятельность, коррекционно-развивающая Аеятельность, экспертно-консультативная Аеятельность

\section{Основные положения}

- модернизация системы образования Аетей с ограниченными возможностями зАоровья требует разработки Аифрференцированного психологического сопровожАения Аетей с залержкой психического развития, обеспечивающего реализацию их особых образовательных потребностей;

- в качестве базовой деятельности психолога, на результатах которой выстраиваются и реализуются иные ее вилы (коррекционно-развивающий и экспертноконсультативный), рассматривается Аиагностическая Аеятельность, охватывающая основной спектр особенностей и возможностей ребенка с ЗПР, опреАеляющих качество его интеграции в образовательную и социальную среды;

- установлено, что психологическое сопровожАение Аетей с ЗПР АОлжно носить системный характер, прелполагающий возможность комплексной реализации основных виАОв Аеятельности психолога, обеспечивающего сопровожАение, а также созАание условий и определение зон продуктивного и гибкого взаимодействия психолога с Аругими специалистами и родителями ребенка.

\section{Для цитирования}

Бабкина Н.В. Система психологического сопровождения образования детей с задержкой психического развития // Российский психологический журнал. 2018. Т. 15 , № 3. C. 52-69. DOI: 10.21702/rpj.2018.3.3

Материалы статьи получены 01.11.2017 


\title{
System of Psychological Support for Education of Children with Mental Development Delay
}

\author{
Nataliya V. Babkina \\ Institute of Special Education of Russian Academy of Education, Moscow, Russian Federation \\ E-mail: natali.babkina@mail.ru
}

\begin{abstract}
Introduction. The paper discusses the issues of psychological support for children with Mental Development Delay (MDD) who represent the majority of school children in the inclusive educational environment. The novelty of the study lies in describing the main types and fields of professional activities of educational psychologists and in constructing an integrated system of the differentiated psychological support for education of this category of children, taking into account variability in their developmental levels at the beginning of formal schooling.
\end{abstract}

Theoretical Basis. This section provides the methodological foundations for the study, including (a) the basic provisions of psychology of children with special needs and correctional pedagogy, based on Vygotsky's cultural-historical theory; (b) the sociocultural approach to the analysis of development of educational practice and to the implementation of objectives of psychology of children with special needs at each stage of the development of education for children with disabilities; and (c) the methodology of psychological support for the educational process. The authors (a) described modern approaches to the organization of psychological support for children with MDD and its objectives under modernization of the educational system and (b) analyzed the necessary content and conditions for education of primary school children aimed at meeting their special educational needs.

Results and Discussion. The authors consider psychological support for children with MDD as a systematic realization of the main types of an educational psychologist's professional activity. Types of this activity are differentiated according to the major goals of modern educational practice and contribute to successful learning and development of every child. The main objectives of such support are as follows: (a) identification, and prevention or elimination of the imbalance between kids' education and development, taking into account their individual abilities; (b) correction of secondary developmental disorders manifested in cognitive, emotional, and socio-behavioral spheres; and (c) creation of conditions for socio-psychological adaptation of the child's personality. The authors described various types of an educational psychologist's professional responsibilities, including diagnostic, correctional and developmental, 


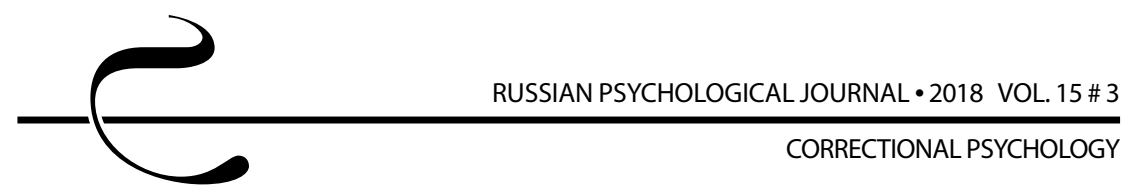

expert and consultative activities. The paper concludes with the provision of criteria for assessing the effectiveness of psychological support.

\section{Keywords}

modernization of education, inclusion, mental development delay, special educational needs, psychological support, psychologist's professional responsibilities, differential approach, diagnostic activities, correctional and developmental activities, expert and consultative activities

\section{Highlights}

- The process of modernization of education for children with disabilities requires the development of targeted psychological support for children with MDD in order to meet their special educational needs.

- Diagnostic activity is the main among professional responsibilities of an educational psychologist. This activity forms the basis for implementing other types of professional activities (correctional and developmental, expert and consultative).

- Diagnostic activity addresses the whole range of main characteristics and abilities of children with MDD, determining the quality of their integration into the educational and social environment.

- Psychological support for children with MDD should be systematic, encompassing the entire array of professional activities of an educational psychologist and should enable creation of conditions for productive and flexible interactions of psychologists with other specialists and with parents of children with special educational needs.

\section{For citation}

Babkina N.V. System of Psychological Support for Education of Children with Mental Development Delay. Rossiiskii psikhologicheskii zhurnal - Russian Psychological Journal, 2018, V. 15, no. 3, pp. 52-69 (in Russian). DOI: 10.21702/rpj.2018.3.3

Original manuscript received 01.11.2017

\section{Введение}

Современный этап реформирования системы образования детей с ограниченными возможностями здоровья (ОВ3) характеризуется активным внедрением интегрированной и инклюзивной его форм, обеспечивающих совместное обучение таких детей с детьми без ограничений здоровья в общеобразовательных организациях. Содержание и условия образования детей с ОВ3 определяются Федеральным государственным образовательным стандартом начального общего образования, в котором акцентируется внимание на неоднородности состава детей внутри каждой нозологической категории, 
предполагающей вариативность содержания образовательных программ, видов и объемов необходимой им психолого-педагогической помощи.

Дети с задержкой психического развития (3ПР) являются не только наиболее многочисленной группой в сравнении с другими категориями детей с ОВ3, но и наиболее представленной в структурах инклюзивного образования (по данным Статистического бюллетеня «Образование в России - 2015», из 449,5 тыс. школьников с ОВ3 и инвалидностью - 187,9 тыс. школьников с ЗПР. В условиях инклюзии обучается 95,7 тыс. детей с 3ПР из 159,3 тыс. детей с ОВ3 и инвалидностью [1], причем эта статистика не учитывает «не диагностированных» детей, испытывающих стойкие трудности в обучении. -Прим. aвт.). Кроме того, дети с ЗПР характеризуются крайней неоднородностью состава, которая обусловлена значительным разнообразием этиологических факторов, порождающих данный вид психического дизонтогенеза и определяющих значительный диапазон выраженности нарушений - от состояний, приближающихся к уровню возрастной нормы, до состояний, требующих отграничения от умственной отсталости.

Этот факт представляется крайне важным в контексте цели и задач проведенного исследования, поскольку он со всей очевидностью предполагает необходимость учета существующих различий между детьми с ЗПР в определении содержания и организации практики их комплексного сопровождения специалистами (психологами, учителями-дефектологами, врачами) в условиях интегрированного обучения. При этом роль психолога, в силу особенностей содержания его обязательных профессиональных компетенций (подготовленность в области психологической диагностики и психологической коррекции нарушений психического развития, информированность в области дефектологии и клинической психологии), должна являться ведущей и, кроме того, координирующей работу других специалистов. Многофункциональная деятельность психолога, опирающаяся на перечисленные выше его компетенции, дает основания для выделения ее в достаточно автономную областьпсихологическое сопровождение образования детей с ЗПР.

Внимание к различным аспектам сопровождения детей с ЗПР дошкольного, младшего школьного и подросткового возрастов отражено в работах Н.Л. Белопольской, С.А. Домишкевича, О.В. Защиринской, Е.Л. Инденбаум, Т.Н. Князевой, Л.В. Кузнецовой, В.И. Лубовского, И.И. Мамайчук, Е.С. Слепович, М.М. Семаго, Н.Я. Семаго, У.В. Ульенковой и др. Но при наличии признания необходимости психологического сопровождения детей с ЗПР и отдельных продуктивных попыток реализации конкретных его направлений в настоящее время отсутствует системный и дифференцированный подход к их психологическому сопровождению, учитывающий вариативность трудностей развития школьников данной категории и причин, лежащих в их основе. 
Таким образом, целью многолетнего исследования [2], основные результаты которого представлены в статье, было обоснование видов деятельности педагога-психолога, а также разработка направлений дифференцированного психологического сопровождения детей с задержкой психического развития в современной образовательной среде. Результаты проведенного исследования были апробированы в школах Москвы (ГБОУ школы №№ 1478, 922, 1666, 2110 и др.) и внедрены в практику образования детей с ЗПР во многих регионах Российской Федерации (Москве и Московской обл., Курской обл., Иркутской обл., Красноярском крае, Хабаровском крае, Самарской обл., Мурманской обл., Алтайском крае, Республике Мордовия и др.).

\section{Теоретическое обоснование}

Происходившее в последние 20 лет преобразование государственной политики в области специального образования, ориентированное на решение задач социальной интеграции людей с различными «особыми нуждами», и предполагающее в качестве желаемого результата достижение каждым таким человеком оптимального для него качества жизни, потребовало и уточнения приоритетов в развитии специальной психологии. Генеральный курс на интеграцию систем общего и специального образования определил особую актуальность разработки методов, подходов и условий специальной психологической поддержки ребенка, подростка, взрослого человека, испытывающих разного рода трудности в обучении, социальной адаптации и социализации в целом. В контексте провозглашенной специальной психологией важнейшей ее задачи в области образования лиц с ограниченными возможностями здоровья - гармонизачии отношений между обучением и развитием - появилась потребность в постановке новых задач и расширении спектра исследований в этой предметной области. Так, в настоящее время активно разрабатываются вопросы, связанные с изучением проблемы социально-эмоционального развития детей с ОВ3 и проектированием соответствующего направления специальной образовательной практики; инициируются исследования, направленные на разработку содержания деятельности психолога, ориентированной на поддержку семьи и ближайшего социального окружения ребенка с ОВ3, которые рассматриваются как важнейший ресурс коррекционно-развивающей работы $[3,4,5,6,7]$.

В числе главных задач специальной психологии на современном этапе ее развития становятся [4]:

- выявление особых образовательных потребностей людей, по тем или иным причинам выпадающих из системы образования, ориентированной на нормальный тип развития; 
- определение психологических условий реализации этих особых потребностей в различных формах обучения и воспитания.

Категория «особые образовательные потребности» является одной из центральных категорий понятийного аппарата специальной психологии и коррекционной педагогики. И хотя выделение и описание особых образовательных потребностей имеет уже достаточно длительную историю, до сих пор не существует единых, согласованных представлений об их содержании, значении и месте, которое они занимают в системах образования детей, наделенных такими потребностями $[4,7,8,9]$.

Впервые в контексте культурно-исторической теории Л.С. Выготского содержание термина «особые образовательные потребности» было раскрыто Е.Л. Гончаровой и О.И. Кукушкиной. Оно органично отражает традиционное для отечественной дефектологии понимание ребенка с нарушениями в развитии как нуждающегося в «обходных путях» решения задач его культурного развития, которые в условиях нормы решаются традиционными, укоренившимися в культуре способами воспитания и принятыми в обществе способами массового образования $[10,11]$.

Таким образом, в центре внимания специальных психологов теперь находятся уже не столько сами особенности психического развития детей с ОВ3, сколько потребности конкретного ребенка, определяемые этими особенностями и задающие ориентиры для создания оптимальных образовательных условий, обеспечивающих удовлетворение этих потребностей. А в качестве перспективной задачи специальной психологии выделяется необходимость организации психологического сопровождения образовательной и сочиальной интеграции.

С позиций задач нашего исследования, наиболее близкой в концептуальном и содержательном плане представляется парадигма сопровождения, разработанная М.Р. Битяновой [12]. И хотя она центрируется на социально-психологических аспектах определения роли, содержания и организации этого процесса, многие положения, сформулированные автором, продуктивно ассоциируются с задачами и форматами деятельности специального психолога, сопровождающего образование детей с ЗПР, а именно: специалист организует деятельность как психологическую практику, со своими внутренними целями и ценностями, органично вплетая ее в ткань учебно-воспитательной педагогической системы и делая ее самостоятельной, но не чужеродной частью этой системы. В рамках данного подхода сопровождение определяется как система профессиональной деятельности психолога, направленной на создание социально-психологических условий для успешного обучения и психологического развития ребенка в ситуациях школьного взаимодействия. 


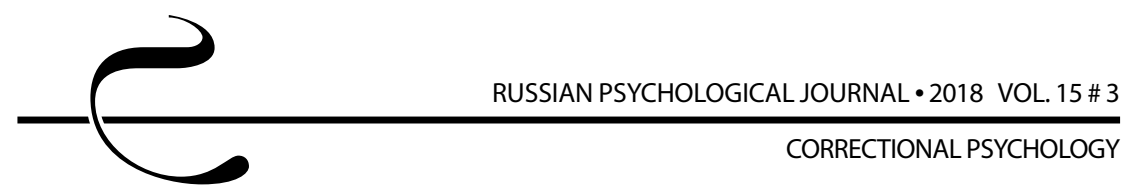

Анализ научно-исследовательских разработок, прямо или косвенно относящихся к проблеме сопровождения детей с ЗПР (Н.Л. Белопольская, Н.Ю. Борякова, Е. Е. Дмитриева, А.О. Дробинская, Г.И. Ефремова, Е.Л. Инденбаум, И. К. Йокубаускайте, Т.Н. Князева, И. А. Коробейников, Т.Н. Павлий, Е.С. Слепович, Р.Д. Тригер, У. В Ульенкова и др.), позволяет утверждать, что несмотря на признание высокой значимости этой деятельности, в настоящее время отсутствует целостный концептуальный подход к психологическому сопровождению, учитывающий неоднородность развития школьников данной категории и ориентированный на достижение целей современного образования детей с особыми образовательными потребностями, нашедшими отражение в Концепции специального стандарта начального школьного образования детей с ОВ3 [11].

Многие авторы признают, что важнейшей составляющей психологического сопровождения является психологическая диагностика, и от ее качества во многом зависит эффективность всей системы сопровождения ребенка с 3ПР $[13,14,15,16]$. Результаты такой диагностики должны способствовать распознаванию вероятного генезиса тех или иных трудностей развития ребенка и одновременно соотноситься с содержанием задач коррекционнопедагогической практики.

Нами предпринята попытка описания типологических вариантов задержки психического развития $[2,17]$, обосновывающих особые образовательные потребности разных групп детей, входящих в данную категорию психического дизонтогенеза, и задающих ориентиры при проектировании целостной системы дифференцированного психологического сопровождения образования школьников с ЗПР. В качестве основных задач сопровождения мы выделяем: выявление, устранение и предотвращение дисбаланса между процессами обучения и развития детей с учетом их индивидуальных возможностей; коррекцию вторичных нарушений развития, проявляющихся в когнитивной, эмоциональной и социально-поведенческой сферах; создание условий для социально-психологической адаптации личности ребенка.

\section{Результаты и их обсуждение}

Мы рассматриваем психологическое сопровождение детей с ЗПР как планомерную реализацию основных видов профессиональной деятельности психолога, дифференцированных в соответствии с актуальными задачами современной образовательной практики и способствующих в своей совокупности успешному обучению и развитию каждого ребенка с 3ПР [2].

Решение перечисленных выше задач сопровождения требует описания диапазона профессионального участия и специфики направлений работы 
психолога, а также конкретизации спектра задач и содержательного наполнения его деятельности.

В качестве базового компонента психологического сопровождения, позволяющего осуществить дифференцированный (индивидуализированный) подход к определению образовательных и компенсаторных возможностей детей с ЗПР и выделению приоритетов коррекционной работы, формулировать рекомендации для педагогов и родителей, осуществлять мониторинг развития ребенка, мы рассматриваем диагностическую деятельность психолога. При анализе результатов диагностики мы предлагаем использовать систему параметров оценки качественных характеристик:

- познавательной деятельности;

- организации и продуктивности мыслительной деятельности (саморегуляции, целенаправленности деятельности, умственной работоспособности);

- коммуникации (в условиях учебной деятельности и вне учебной деятельности);

- обучаемости (с выделением когнитивного и мотивационного ее ресурсов).

Предложенная нами схема построения типологии [17], опирающаяся на детализированное феноменологическое описание групп детей с ЗПР на начальном этапе школьного обучения, дифференцированных на основе наиболее вероятных комбинаций признаков задержанного развития и степени их выраженности, убедительно показывает, что рекомендации по сопровождению учеников, относящихся к каждой из выделенных групп, не могут быть идентичными, причем это касается как деятельности психолога, так и работы учителя, и участия родителей. Коллегиальное обсуждение результатов обследования всеми специалистами психолого-медико-педагогического консилиума (ПМПК) позволяет выработать единое представление о характере и особенностях развития ребенка, определить общий прогноз его дальнейшего развития, комплекс необходимых коррекционно-развивающих мероприятий и разработать согласованную программу действий.

Коррекционно-развивающая деятельность в рамках психологического сопровождения ребенка с 3ПР в условиях образования включает: выбор специальных методик и программ коррекционно-развивающих курсов в соответствии с результатами диагностического обследования и выделенными на их основе приоритетами коррекционно-развивающей работы; проведение индивидуальных и групповых коррекционно-развивающих занятий, направленных на компенсацию имеющихся у ребенка нарушений и формирование сферы жизненной компетенции.

Основные направления коррекционной работы, определяемые спецификой психической деятельности, поведения и социально-эмоционального развития данной категории детей включают: 


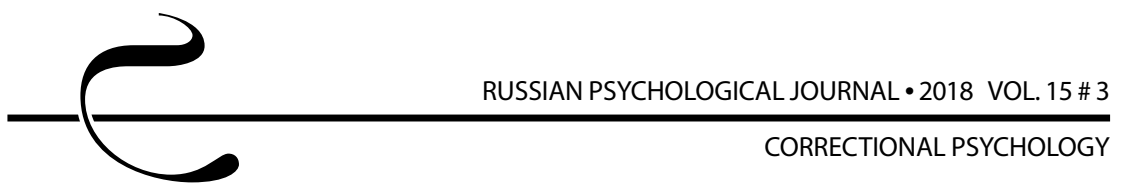

- развитие эмоционально-личностной сферы и коррекциюее недостатков;

- развитие познавательной сферы и целенаправленное формирование высших психических функций;

- формирование произвольной регуляции деятельности и поведения;

- формирование сферы социальных коммуникаций.

Все перечисленные направления коррекционной работы с детьми с ЗПР, в разное время и в разных масштабах, являлись предметом наших собственных научно-методических разработок $[17,18,19,20]$. В результате часть из них была использована при подготовке нормативных докуменТОВ (ФГОС НОО обучающихся с ОВЗ и Примерной адаптированной основной общеобразовательной программы для обучающихся с 3ПР), описывающих и регламентирующих цели, содержание и организацию образования данной категории детей.

Одним из центральных направлений коррекционно-развивающей работы с детьми с ЗПР, реализующей их особые образовательные потребности, является формирование саморегуляции в учебно-познавательной деятельности. Значимость этого направления обоснована результатами многочисленных современных отечественных и зарубежных исследований (Н.В. Бабкина, В.И. Моросанова, Т.Г. Фомина, И.Н. Бондаренко, А. Bandura, М. М. Chemers, A. Furnham, A. M. Grant, M. Komarraju, P. Rosander, R. Steinmayr, A. Wigfield и др.), установивших взаимосвязи между мотивацией учения, уровнем развития и стилевыми особенностями осознанной саморегуляции. Показано, что учащиеся с более высокой (в сравнении с другими сверстниками) мотивацией и развитой саморегуляцией достигают в учебной деятельности более высоких результатов, позитивнее относятся к учению, успешнее адаптируются к изменяющимся условиям учебного процесса $[21,22,23,24$, $25,26,27,28,29,30]$.

Нами разработана и широко апробирована комплексная программа формирования саморегуляции у младших школьников с 3ПР, включающая: методические рекомендации по организации индивидуальных и групповых занятий психолога, учитывающие уровень сформированности у ребенка осознанной регуляции познавательной деятельности; рекомендации учителям по осуществлению индивидуального и дифференцированного подхода к учащимся; рекомендации родителям [20].

Экспертно-консультативная и координационная деятельность психолога в рамках сопровождения детей с ЗПР интегрирует результаты их диагностического обследования и коррекционной работы, а также способствует продуктивной координации усилий основных субъектов сопровождения (педагога, учителя-дефектолога, родителей ребенка) [31]. Она включает следующие направления: психологическое просвещение и консультирование 
педагогов; организацию продуктивного взаимодействия с родителями; комплексный мониторинг развития ребенка; экспертную деятельность по оценке адекватности выбранного образовательного маршрута и его корректировке; экспертизу образовательной среды с точки зрения соответствия особым образовательным потребностям школьника; координацию взаимодействия с психолого-медико-педагогической комиссией (ПМПК) и ресурсными центрами.

Задачи, содержание и методы работы психолога с педагогами и родителями дифференцируются в зависимости от варианта развития ребенка и условий его обучения (инклюзия или специальный класс).

Одна из главных задач психолога во взаимодействии с учителем - обучение педагога целенаправленному наблюдению за ребенком, фиксации тех или иных трудностей и своевременному обращению за помощью к психологу; помощь в осмыслении результатов проведенного обучения в проекции на развитие ребенка, соотнесении «шагов» в развитии ребенка с «шагами» в методике обучения. Считаем необходимым обратить внимание на особую значимость психологического просвещения и консультирования педагогов, обучающих детей с ЗПР в условиях инклюзии, в связи с отсутствием у большинства из них специальной подготовки. Психолог помогает педагогу в выборе индивидуально-ориентированных методов и приемов работы с обучающимися, в оптимизации методического обеспечения и организационных условий оценки достижений ребенка в усвоении образовательной программы, включающих его приобретения в сфере жизненной компетенции.

Помощь психолога учителю-дефектологу заключается в совместном определении зоны ближайшего развития ученика, в обучении пониманию причин затруднений в учебной деятельности, связанных с недостаточностью эмоционально-мотивационного или когнитивного ресурсов обучаемости, в проектировании необходимых индивидуальных образовательных условий и выборе соответствующих специальных методов и приемов обучения.

Задачи психолога по отношению к родителям школьника с ЗПР: максимальное их привлечение к участию в образовательном процессе; помощь в адекватном оценивании возможностей своего ребенка, понимании его трудностей и определении ресурсов в решении поставленных задач обучения и воспитания; повышение мотивации семьи на сотрудничество со школьными специалистами.

Осуществление экспертной деятельности проводится на междисциплинарной основе с участием всех специалистов ПМПК образовательной организации. Результатом такой работы является отслеживание (мониторинг) продвижения ребенка в усвоении академических знаний и формировании 


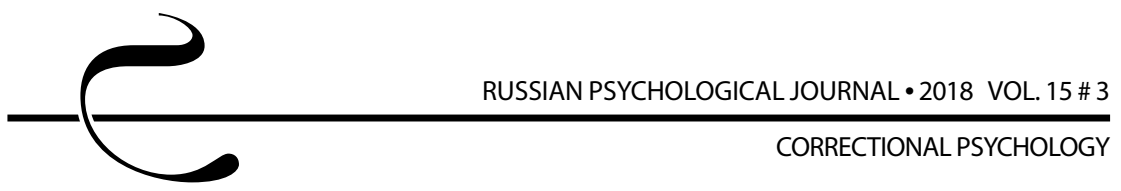

сферы жизненной компетенции, что позволяет, с одной стороны, оценивать адекватность выбранного образовательного маршрута и при необходимости вносить в него корректировки, а с другой - предоставлять администрации образовательной организации объективную информацию, позволяющую осуществлять анализ воздействия традиционных и инновационных образовательных и психолого-педагогических технологий на качество обучения и личностные изменения школьников.

Еще одно направление экспертной деятельности психолога-психологическая экспертиза соответствия образовательной среды особым образовательным потребностям и индивидуальным особенностям обучающихся с ЗПР; защита ребенка от деструктивного воспитательного и психологического влияния; обеспечение школьнику субъективного ощущения комфорта и уверенности в своих силах.

\section{Заключение}

Проведенное исследование позволило обосновать необходимость целостного концептуального подхода к психологическому сопровождению детей с ЗПР, учитывающего неоднородность развития школьников данной категории и ориентированного на достижение целей современного образования детей с ОВЗ.

На основе результатов анализа существующих подходов к содержанию и организации психологического сопровождения детей в образовательной среде, а также на основе интеграции собственного опыта работы в этой области нами выделены и описаны три основных взаимосвязанных вида деятельности, определяющие функционал специального психолога, обеспечивающего профессиональное сопровождение детей с ЗПР в современной образовательной среде - диагностическая, коррекционно-развивающая, экспертно-консультативная.

Для оценки эффективности психологического сопровождения как системно организованного процесса мы предлагаем критерии, включающие: оценку полноты и качества реализации всех основных видов деятельности психолога; соответствие созданных совместно с другими специалистами дифференцированных условий особым образовательным потребностям ребенка с ЗПР; динамику продвижения ребенка в психофизическом развитии и освоении образовательной программы. Залогом продуктивной коррекционно-развивающей и экспертно-консультативной деятельности и эффективности психологического сопровождения в целом является методологически обоснованная и корректно организованная диагностическая деятельность. 
КОРРЕКЦИОННАЯ ПСИХОЛОГИЯ

\section{Благодарности}

Исследование выполнено в рамках Государственного задания Минобрнауки РФ ФГБНУ ИКП РАО (№ 25.8968.2017/8.9 «Современная система медико-психолого-педагогической помощи детям с ОВ3 дошкольного и школьного возраста»).

\section{Acknowledgments}

Supported by the Ministry of Education and Science of the Russian Federation for studying the Modern System of Medical, Psychological and Pedagogical Assistance to Preschool and School-Age Children with Limited Health Possibilities (project no. 25.8968.2017/8.9).

\section{Литература}

1. Образование в России - 2015: Статистический бюллетень. М.: МИРЭА, 2016. 518 c.

2. БабкинаН.В. Психологическое сопровождение младших школьников с задержкой психического развития: дисс. ... д. психол. наук. М., 2017. 263 с.

3. Гончарова Е. Л. К вопросу о субъекте психолого-педагогического сопровождения в формирующейся практике комплексной помощи детям раннего возраста // Дефектология. 2009. № 1. С. 45-50.

4. Гончарова Е. Л. Специальная психология // Альманах Института коррекционной педагогики. 2002. № 5. URL: http://alldef.ru/ru/articles/almanah-5 (дата обращения 17.09.2017).

5. Гончарова Е. Л. Эволюция предмета специальной психологии // Воспитание и обучение детей с нарушениями развития. 2015. № 8. С. 5-7.

6. Малофеев Н. Н. Научные достижения отечественной дефектологии как базис современной профилактической, коррекционной и реабилитационной помощи детям с нарушениями развития // Воспитание и обучение детей с нарушениями развития. 2014. № 2. С. 3-10.

7. Никольская О. С., Баенская Е. Р. Особые образовательные потребности детей с расстройствами аутистического спектра в период начального школьного образования // Воспитание и обучение детей с нарушениями развития. 2015. № 2. С. 9-17.

8. АлехинаС.В. Особые образовательныепотребности как категория инклюзивного образования // Российский научныйжурнал. 2013. № 5 (36). С. 132-139.

9. Лубовский В. И. Особые образовательные потребности // Психологическая наука и образование psyedu.ru. 2013. № 5. C. 61-66. URL: http:// psyedu.ru/journal/2013/5/Lubovskiy.phtml (дата обращения: 20.08.2017).

10. Гончарова Е. Л., Кукушкина О. И. Ребенок с особыми образовательными потребностями // Альманах Института коррекционной педагогики. 2002. № 5. URL: http://alldef.ru/ru/articles/almanah-5/rebenok-s-osobymiobrazovatelnymi-potrebnostjami (дата обращения 17.09.2017). 
11. Малофеев Н. Н., Кукушкина О. И., Никольская О. С., Гончарова Е. Л. Концепция Специального Федерального государственного образовательного стандарта для детей с ограниченными возможностями здоровья. М.: Просвещение, 2013. 42 с.

12. Битянова М. Р. Организация психологической работы в школе. М.: Совершенство, 1997. 298 с.

13. Коробейников И. А. Диагностика нарушений психического развития у детей в контексте проблем интеграции междисциплинарного знания // Дефектология. 2004. № 1. С. 54-60.

14. Домишкевич С. А. Функционально-уровневый подход в психодиагностике, коррекционно-развивающей работе и консультировании. Ч. 1. Функционально-уровневый подход в психолого-педагогической диагностике. Иркутск: Изд-во ИГПУ, 2002. 40 с.

15. Инденбаум Е. Л. Школьники с легкими формами интеллектуальной недостаточности: психолого-педагогическая диагностика и характеристики психосоциального развития: монография. Иркутск: Изд-во ВСГАО, 2012. $180 \mathrm{c}$.

16. Белопольская Н. Л. Экспериментально-психологические исследования личности детей с задержкой психического развития. М.: Когито-Центр, 2013. 32 c.

17. Коробейников И. А., Бабкина Н. В. Дифференциация образовательных потребностей как основа дифференцированных условий образования детей с задержкой психического развития // Дефектология. 2017. № 2. С. 3-13.

18. Бабкина Н. В. Жизненные компетенции как неотъемлемая составляющая содержания образования детей с задержкой психического развития // Клиническая и специальная психология. 2017. T. 6, № 1. C. 138-156. DOI: $10.17759 /$ cpse.2017060109

19. Бабкина Н. В. Основные направления и содержание коррекционной работы с младшими школьниками с задержкой психического развития // Дефектология. 2016. № 2. С. 53-59.

20. Бабкина Н. В. Роль осознанной саморегуляции в реализации когнитивных и личностных ресурсов ребенка с задержкой психического развития // Клиническая и специальная психология. 2016. Т. 5, № 3. С. 40-55.

21. Бондаренко И. Н., Моросанова В. И., Драпкин И. С., Путко Н. А. Актуалгенез осознанной саморегуляции в ситуации выбора уровня сложности учебных заданий // Экспериментальная психология. 2014. Т. 7, № 2. С. 64-81.

22. Моросанова В. И., Цыганов И. Ю., Ванин А. В., Филиппова Е. В. Осознанная саморегуляция и отношение к учению: их взаимосвязь и вклад в успешность обучения // Вопросы психологии. 2015. № 5. С. 32-45. 
23. Bandura A., Caprara G. V., Barbaranelli C., Gerbino M., Pastorelli C. Role of Affective Self-Regulatory Efficacy in Diverse Spheres of Psychosocial Functioning // Child Development. 2003. Vol. 74, Issue 3. P. 769-782. DOI: 10.1111/1467-8624.00567

24. Chemers M. M., Hu L., Garcia B. F. Academic self-efficacy and first-year college student performance and adjustment // Journal of Educational Psychology. 2001. Vol. 93 (1). P. 55-64. DOI: 10.1037/0022-0663.93.1.55

25. Furnham A., Moutafi J., Chamorro-Premuzic T. Personality and Intelligence: Gender, the Big Five, Self-Estimated and Psychometric Intelligence // International Journal of Selection and Assessment. 2005. Vol. 13, Issue 1. P. 11-24. DOI: $10.1111 /$ j.0965-075X.2005.00296.x

26. Grant A. M., Sonnentag S. Doing good buffers against feeling bad: Prosocial impact compensates for negative task and self-evaluations // Organizational Behavior and Human Decision Processes. 2010. Vol. 111, Issue 1. P. 13-22. DOI: $10.1016 /$ j.obhdp.2009.07.003

27. Komarraju M., Karau S. J., Schmeck R. R. Role of the Big Five personality traits in predicting college students' academic motivation and achievement // Learning and Individual Differences. 2009. Vol. 19, Issue 1. P. 47-52. DOI: 10.1016/j.lindif.2008.07.001

28. Rosander P., Bäckström M., Stenberg G. Personality traits and general intelligence as predictors of academic performance: A structural equation modelling approach // Learning and Individual Differences. 2011. Vol. 21, Issue 5. P. 590-596. DOI: 10.1016/j.lindif.2011.04.004

29. Steinmayr R., Bipp T., Spinath B. Goal orientations predict academic performance beyond intelligence and personality // Learning and Individual Differences. 2011. Vol. 21, Issue 2. P. 196-200. DOI: $10.1016 /$ j.lindif.2010.11.026

30. Wigfield A., Klauda S. L., Cambria J. Influences on the development of academic self-regulatory processes // Handbook of Self-Regulation of Learning and Performance / B. J. Zimmerman, D. H. Schunk (Eds.). N. Y.: Routledge Press, 2011. P. 33-48.

31. Коробейников И. А., Бабкина Н. В. Консультативный ресурс психологического диагноза при нарушениях психического развития у детей // Консультативная психология и психотерапия. 2017. Т. 25, № 4. С. 11-22. DOI: $10.17759 /$ срр.2017250402

\section{References}

1. Obrazovanie v Rossii - 2015: Statisticheskii byulleten' [Education in Russia 2015: Statistical bulletin]. Moscow, Moscow Technical University Publ., 2016. $518 \mathrm{p}$.

2. Babkina N. V. Psikhologicheskoe soprovozhdenie mladshikh shkol'nikov 
s zaderzhkoi psikhicheskogo razvitiya [Psychological support of junior schoolchild with mental development delay]. Diss. Dr. Sci. (Psych.). Moscow, 2017. 263 p.

3. Goncharova E. L. On the subject of psychological and pedagogical support in the emerging practice of comprehensive assistance to toddlers. Defektologiya - Defectology, 2009, no. 1, pp. 45-50 (in Russian).

4. Goncharova E. L. Special psychology. Al'manakh Instituta korrektsionnoi pedagogiki-Almanac of the Institute of Special Education, 2002, no. 5. Available at: http://alldef.ru/ru/articles/almanah-5 (Accessed 17 September 2017).

5. Goncharova E. L. Evolution of the subject of special psychology. Vospitanie i obuchenie detei s narusheniyami razvitiya - Upbringing and Teaching Children with Developmental Disorders, 2015, no. 8, pp. 5-7 (in Russian).

6. Malofeev N. N. Scientific achievements of domestic defectology as the basis of modern preventive, corrective and rehabilitative care for children with developmental disorders. Vospitanie i obuchenie detei s narusheniyami razvitiya - Upbringing and Teaching Children with Developmental Disorders, 2014, no. 2, pp. 3-10 (in Russian).

7. Nikolskaya O. S., Baenskaya E. R. Special educational needs of children with autism spectrum disorders in the period of primary school education. Vospitanie iobuchenie detei s narusheniyami razvitiya-Upbringing and Teaching Children with Developmental Disorders, 2015, no. 2, pp. 9-17 (in Russian).

8. Alekhina S. V. Special educational needs as a category of inclusive education. Rossiiskii nauchnyi zhurnal - Russian Scientific Journal, 2013, no. 5 (36), pp. 132-139 (in Russian).

9. Lubovsky V. I. Special educational needs. Psychological-Educational Studies (Psyedu.ru), 2013, no. 5, pp. 61-66 (in Russian). Available at: http:// psyedu.ru/journal/2013/5/Lubovskiy.phtml (Accessed 20 August 2017).

10. Goncharova E. L., Kukushkina O. I. A child with special educational needs. Al'manakh Instituta korrektsionnoi pedagogiki - Almanac of the Institute of Special Education, 2002, no. 5 (in Russian). Available at: http:// alldef.ru/ru/articles/almanah-5/rebenok-s-osobymi-obrazovatelnymipotrebnostjami (Accessed 17 September 2017).

11. Malofeev N. N., Kukushkina O. I., Nikol'skaya O. S., Goncharova E. L. Kontseptsiya Spetsial'nogo Federal'nogo gosudarstvennogo obrazovatel'nogo standarta dlya detei s ogranichennymi vozmozhnostyami zdorov'ya [Concept of a special federal education standard for children with disabilities]. Moscow, Prosveshchenie Publ., 2013. 42 p.

12. Bityanova M. R. Organizatsiya psikhologicheskoi raboty v shkole [Organization of psychological work at school]. Moscow, Sovershenstvo Publ., 1997. 298 p. 
13. Korobeinikov I. A. Diagnosis of mental development disorders in children in the context of integration problems of interdisciplinary knowledge. Defektologiya - Defectology, 2004, no. 1, pp. 54-60 (in Russian).

14. Domishkevich S. A. Funktsional'no-urovnevyi podkhod v psikhodiagnostike, korrektsionno-razvivayushchei rabote i konsul'tirovanii. Ch. 1. Funktsional'nourovnevyi podkhod v psikhologo-pedagogicheskoi diagnostike [Functionallevel approach in psychodiagnostics, correction-developing work, and psychological consultation. Part 1. Functional-level approach in psychodiagnostics, correction-developing work, and psychological consultation]. Irkutsk, ISPU Publ., 2002. 40 p.

15. Indenbaum E. L. Shkol'niki s legkimi formami intellektual'noi nedostatochnosti: psikhologo-pedagogicheskaya diagnostika i kharakteristiki psikhosotsial'nogo razvitiya [Schoolchildren with mild intellectual disabilities: Psychological and pedagogical diagnostics and characteristics of psychosocial development]. Irkutsk, East-Siberian State Academy of Education Publ., 2012. 180 p.

16. Belopol'skaya N. L. Eksperimental'no-psikhologicheskie issledovaniya lichnosti detei s zaderzhkoi psikhicheskogo razvitiya [Experimental and psychological studies on children with mental development delay]. Moscow, Kogito-Tsentr Publ., 2013. 32 p.

17. Korobeinikov I. A., Babkina N. V. Differentiation of educational needs as the basis for differentiated conditions for the education of children with mental retardation. Defektologiya - Defectology, 2017, no. 2, pp. 3-13 (in Russian).

18. Babkina N. B. Life competences as an integral part of the content of education for children with mental development delay. Klinicheskaya i spetsial'naya psikhologiya - Clinical and Special Psychology, 2017, V. 6, no. 1, pp. 138-156 (in Russian). DOI: $10.17759 /$ cpse.2017060109

19. Babkina N. V. Main directions and content of correctional work with junior schoolchildren with mental development delay. Defektologiya-Defectology, 2016, no. 2, pp. 53-59 (in Russian).

20. Babkina N. The role of conscious self-regulation in realization of cognitive and personal resources in a child with mental development delay. Klinicheskaya ispetsial'naya psikhologiya - Clinical and Special Psychology, 2016, V. 5, no. 3, pp. 40-55 (in Russian).

21. Bondarenko I. N., Morosanova V. I., Drapkin I. S., Putko N. A. Actual genesis of conscious self-regulation in a situation of choosing the level of sophistication of learning tasks. Experimental psychology-Eksperimental'naya psikhologiya, 2014, V. 7, no. 2, pp. 64-81 (in Russian).

22. Morosanova V. I., Tsyganov I. Yu., Vanin A. V., Filippova E. V. Conscious selfregulation and attitude to learning: Their interconnection and influence on performance. Voprosy psikhologii, 2015, no. 5, pp. 32-45 (in Russian). 


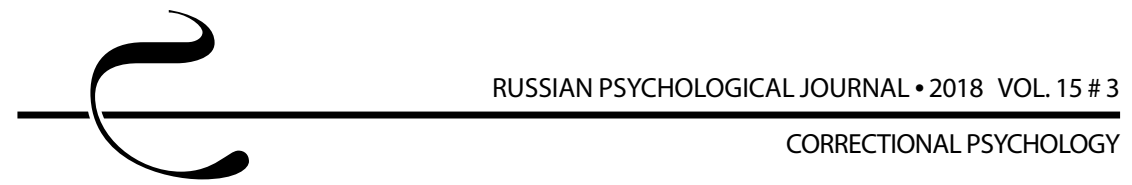

23. Bandura A., Caprara G. V., Barbaranelli C., Gerbino M., Pastorelli C. Role of affective self-regulatory efficacy in diverse spheres of psychosocial functioning. Child Development, 2003, V. 74, Issue 3, pp. 769-782. DOI: 10.1111/1467-8624.00567

24. Chemers M. M., Hu L., Garcia B. F. Academic self-efficacy and first-year college student performance and adjustment. Journal of Educational Psychology, 2001, V. 93 (1), pp. 55-64. DOI: 10.1037/0022-0663.93.1.55

25. Furnham A., Moutafi J., Chamorro-Premuzic T. Personality and intelligence: Gender, the big five, self-estimated and psychometric intelligence. International Journal of Selection and Assessment, 2005, V. 13, Issue 1, pp. 11-24. DOI: 10.1111/j.0965-075X.2005.00296.X

26. Grant A. M., Sonnentag S. Doing good buffers against feeling bad: Prosocial impact compensates for negative task and self-evaluations. Organizational Behavior and Human Decision Processes, 2010, V. 111, Issue 1, pp. 13-22. DOI: 10.1016/j.obhdp.2009.07.003

27. Komarraju M., Karau S. J., Schmeck R. R. Role of the Big Five personality traits in predicting college students' academic motivation and achievement. Learning and Individual Differences, 2009, V. 19, Issue 1, pp. 47-52. DOI: 10.1016/j.lindif.2008.07.001

28. Rosander P., Bäckström M., Stenberg G. Personality traits and general intelligence as predictors of academic performance: A structural equation modelling approach. Learning and Individual Differences, 2011, V. 21, Issue 5, pp. 590-596. DOI: 10.1016/j.lindif.2011.04.004

29. Steinmayr R., Bipp T., Spinath B. Goal orientations predict academic performance beyond intelligence and personality. Learning and Individual Differences, 2011, V. 21, Issue 2, pp. 196-200. DOI:10.1016/j.lindif.2010.11.026

30. Wigfield A., Klauda S. L., Cambria J. Influences on the development of academic self-regulatory processes. In: B. J.Zimmerman, D. H. Schunk (eds.) Handbook of self-regulation of learning and performance. N. Y., Routledge Press, 2011, pp. 33-48.

31. Korobeinikov I. A., Babkina N. V. Consultative resource of psychological diagnosis in children with mental development delay. Konsul'tativnaya psikhologiya i psikhoterapiya - Counseling Psychology and Psychotherapy, 2017, V. 25, no. 4, pp. 11-22 (in Russian). DOl: 10.17759/cpp.2017250402 